\title{
A Review of Insulin Degludec/Insulin Aspart: Pharmacokinetic and Pharmacodynamic Properties and Their Implications in Clinical Use
}

\author{
Hanne Haahr ${ }^{1} \cdot$ Edmond G. Fita $^{2} \cdot$ Tim Heise $^{3}$
}

Published online: 1 October 2016

(c) The Author(s) 2016. This article is published with open access at Springerlink.com

\begin{abstract}
Insulin degludec/insulin aspart (IDegAsp; $70 \%$ IDeg and $30 \%$ IAsp) is a soluble combination of two individual insulin analogues in one product, designed to provide mealtime glycaemic control due to the IAsp component and basal glucose-lowering effect from the IDeg component. The pharmacokinetic and pharmacodynamic characteristics of IDegAsp have been investigated in a series of clinical pharmacology studies with generally comparable designs, methodologies and patient inclusion/ exclusion criteria. The glucose-lowering effect profile of IDegAsp during once-daily dosing at steady state shows distinct and clearly separated action from the prandial and basal components of IDegAsp. The IAsp component provides rapid onset and peak glucose-lowering effect followed by a flat glucose-lowering effect lasting beyond $30 \mathrm{~h}$ due to IDeg. During twice-daily dosing, the distinct peak effect and the flat basal effect are retained following each dose. The pharmacological properties of IDegAsp are maintained in the elderly, children, adolescents, Japanese patients and those with hepatic or renal impairment. The potential clinical benefits associated with the pharmacological properties of IDegAsp have been verified in phase III clinical trials comparing IDegAsp with three other currently available treatment options: premixed insulin, basal-bolus regimens and basal-only therapy. IDegAsp
\end{abstract}

Hanne Haahr

hhaa@novonordisk.com

1 Clinical Pharmacology, Novo Nordisk A/S, Vandtårnsvej 114, 2860 Søborg, Denmark

2 Global Medical Affairs, Novo Nordisk A/S, Vandtårnsvej 114, 2860 Søborg, Denmark

3 Profil Institut für Stoffwechselforschung $\mathrm{GmbH}$, Hellersbergstrasse 9, 41460 Neuss, Germany shows favourable clinical benefits compared with biphasic insulin aspart 30 and is a viable alternative to basal-bolus and basal-only therapy. This review presents the results from clinical pharmacology studies conducted with IDegAsp to date, and extrapolates these results to clinical use of IDegAsp in the context of findings from the IDegAsp clinical therapeutic studies.

\section{Key Points}

There is a clinical need for an insulin combination that can offer both basal and mealtime insulin coverage in one injection in patients with diabetes.

Insulin degludec/insulin aspart (IDegAsp; $70 \%$ IDeg and $30 \%$ IAsp) provides rapid onset and peak glucose-lowering effect due to the bolus IAsp component, as well as a flat and long-lasting glucoselowering effect from the basal IDeg component, during both once- and twice-daily dosing across several different patient populations.

Due to its pharmacological properties, IDegAsp is superior to premixed formulations and may also be an alternative to basal-only and basal-bolus therapy.

\section{Introduction}

Patients with type 2 diabetes mellitus (T2DM) receiving basal insulin who require additional mealtime insulin can intensify treatment either through the addition of mealtime short-acting insulin or by switching to a premixed insulin formulation [1]. Basal-plus (i.e. the addition of one or two 
mealtime injections) or full basal-bolus regimens approach the physiological basal and mealtime insulin responses, albeit with the complexity of up to four or five separate injections. Such treatment regimens with multiple daily injections and frequent blood glucose sampling can be challenging for patients and may decrease treatment adherence [1-3]. Premixed insulin formulations, which cover both basal and mealtime insulin needs in one injection, offer a more convenient alternative, although are relatively inflexible in terms of titration and timing and need to be resuspended before administration, which is an additional burden for patients and is often done incorrectly [1, 4-6]. Although premixed insulin products have provided a simpler treatment option for patients requiring better glycaemic control, and are widely used globally [7], premixed insulin products also carry limitations in their pharmacokinetic and pharmacodynamic properties, as discussed in Sect. 2 of this review. Therefore, there has been a clinical need for a combined insulin formulation that can provide sustained and stable basal insulin coverage together with an effective mealtime bolus dose in one injection.

Insulin degludec/insulin aspart (IDegAsp) is the first soluble combination of two different insulin analogues (70 \% IDeg and $30 \%$ IAsp), providing long and steady basal glucose-lowering effect due to the IDeg component, and mealtime glycaemic control due to the rapid absorption of the IAsp component in a single pen [8]. The pharmacokinetic and pharmacodynamic characteristics of IDegAsp have been investigated in a series of studies, which have shown improvements in pharmacological properties compared with premixed insulin products [9-13]. Furthermore, the potential clinical benefits associated with these properties have been verified in large phase III clinical trials [14-21]. This review discusses the results obtained from the pharmacokinetic and pharmacodynamic studies conducted with IDegAsp to date, and extrapolates the clinical relevance of the observed pharmacokinetic and pharmacodynamic properties of IDegAsp in the context of the findings from the IDegAsp clinical therapeutic studies.

\section{Insulin Formulations to Provide Both Basal and Mealtime Coverage}

\subsection{Limitations of Current Premixed Insulin Formulations}

Current premixed insulin formulations include biphasic human insulin, biphasic insulin aspart (BIAsp) and insulin lispro mix [4]. All of these products contain a fixed proportion of the soluble form of either human insulin, IAsp or insulin lispro, with the remainder consisting of the corresponding protaminated form. Thus, basal and mealtime coverage is provided in one injection. However, there are several limitations associated with premixed insulin formulations. First, the need for adequate and consistent resuspension in order to ensure accurate dosing may introduce substantial variability in the pharmacokinetic and pharmacodynamic response [6]. Second, although protamination results in a protracted absorption of insulin into the circulation, protamination of short-acting insulin only results in intermediate-acting insulin. Thus, the duration of action of premixed insulin products is still shorter than for basal insulin analogues such as insulin glargine (IGlar) and insulin detemir (IDet) [22, 23]. Third, in premixed insulin products, the protaminated fraction interferes with the soluble fraction, leading to an undesired, prolonged glucose-lowering effect from the soluble part, which overlaps with the peak action of the protaminated fraction at approximately $6 \mathrm{~h}$, which is often denoted the 'shoulder effect' [24, 25]. Fourth, formation of insulin-protamine precipitates in the subcutaneous tissue after administration, and subsequent release of insulin into the circulation, represent processes that contribute to variability in both level and duration of insulin action. These limitations may translate into variability in glycaemic control from day to day, incomplete 24-h coverage and, presumably, an increased rate of hypoglycaemia with premixed insulin compared with basal-plus and basal-bolus regimens [26-28].

\subsection{Challenges of Combining a Basal and a Bolus Insulin in a Single Formulation}

The ideal way of providing basal and mealtime insulin coverage in one injection would be to combine a basal and a rapid-acting insulin, in a formulation where the two components act independently, i.e. where the pharmacological properties of both components are preserved. However, prior attempts to combine basal and rapid-acting insulin analogues have been unsuccessful [29, 30].

In order to remain stable in the pen, rapid-acting insulin analogues need to be formulated as a neutral solution, i.e. with a $\mathrm{pH}$ of approximately 7.4 [8]. On the other hand, IGlar requires formulation at acidic $\mathrm{pH} 4$ to stay soluble in the pen. Following subcutaneous administration, due to the shift to physiological $\mathrm{pH}$, IGlar forms microprecipitates in the subcutaneous tissue, from which IGlar slowly dissolves into the circulation [31]. Thus, the mode of protraction for IGlar prevents it from co-formulation with rapid-acting insulin analogues without any impact on the glucose-lowering effect profile of the latter. Indeed, the combination of IGlar and insulin lispro has been shown to change the early glucose-lowering effect profile, resulting in a reduced peak effect and a general right-shift of the bolus-related effect profile [29]. 
IDet, however, is formulated as hexamers in a neutral solution ( $\mathrm{pH}$ 7.4). Subcutaneous injection of IDet leads to dilution of the preservatives present in the pharmaceutical formulation (phenol, cresol and polyol), and hexameric IDet then reaches a hexamer-dihexamer equilibrium [32]. The self-association into dihexamers and the binding to albumin result in protraction of absorption into the circulation [32]. When IDet is co-formulated with IAsp, the selfassociation equilibriums for the two components may lead to the formation of IDet/IAsp hybrid hexamers, which would, in particular, limit the rapid absorption of IAsp [8]. Accordingly, an attempt to combine IDet and IAsp resulted in a reduced and right-shifted early glucose-lowering effect [30].

\subsection{Combination of IDeg and IAsp in a Co-Formulation (IDegAsp)}

IDeg is the most recently developed basal insulin analogue and has been approved in the EU, US and several other countries worldwide [33, 34]. In the pharmaceutical formulation, IDeg exists as highly stable dihexamers in a neutral solution in the presence of phenol and zinc [35]. Upon injection, phenol diffuses and IDeg undergoes a conformational change, leading to formation of soluble multihexamers at the site of injection [35, 36]. Following the gradual diffusion of zinc, the IDeg multihexamers continuously disassemble and release monomers for absorption into the circulation [35]. The stable IDeg dihexamers in the pharmaceutical formulation and the unique multihexamer formation in the subcutaneous tissue made IDeg a promising candidate for co-formulation with IAsp without the risk of hybrid hexamer formation. The association states of IDeg and IAsp in a 70/30 \% co-formulation were investigated through size exclusion chromatography (SEC) studies in conditions simulating the pharmaceutical formulation and the subcutaneous tissue [8]. When IAsp was added to fully dihexameric IDeg in the presence of high concentrations of zinc, the two components coexisted in the formulation as separate molecular entities (IDeg dihexamers and IAsp hexamers, respectively) (Fig. 1a, left panels and 1b). In simulations of the subcutaneous tissue depot, the two components also eluted separately (as IDeg multihexamers and IAsp monomers, respectively) (Fig. 1a, right panels). This suggests that following subcutaneous administration of IDegAsp, the formation of IDeg multihexamers and the disassembly of IAsp from hexamers to monomers occur as discrete processes (Fig. 1c) [8]. Hence, for the first time, a combination of two separate insulin analogues (IDeg and IAsp) has been made possible without changing the pharmacological properties of the individual components. It is important to realise that IDegAsp clearly differentiates from premixed insulin products due to the existence of its insulin components as separate and stable soluble forms in the formulation, thereby avoiding the need for resuspension prior to injection.

\section{Pharmacodynamic Characteristics of IDegAsp}

\subsection{Data Collection Procedures}

In the clinical pharmacology studies investigating the pharmacological properties of IDegAsp, study designs, methodologies and patient inclusion/exclusion criteria were generally standardised and studies were conducted at a limited number of sites to maintain consistency in data collection and analysis.

The 'gold standard' to evaluate the pharmacodynamic properties of exogenous insulin is the euglycaemic glucose clamp. This measures the rate of intravenous glucose infusion needed to maintain the blood glucose concentration at a constant, predetermined, normal level following insulin administration, and uses this rate as a measure of the glucose-lowering effect of the exogenous insulin under investigation [37, 38]. Patients with type 1 diabetes mellitus (T1DM) are the optimal population to evaluate the pharmacodynamic characteristics of exogenous insulin as the euglycaemic clamp results are not affected by endogenous insulin secretion (as would be the case in healthy volunteers or patients with T2DM) or acquired insulin resistance (as would be the case in patients with T2DM).

\subsection{Glucose-Lowering Effect of IDegAsp}

The pharmacodynamic properties of IDegAsp have been investigated during once-daily dosing at steady state in a 30-h euglycaemic glucose clamp in patients with T1DM [9].

The glucose-lowering effect profile of IDegAsp showed distinct and clearly separated action from the prandial and basal components of IDegAsp (Fig. 2). The IAsp component provided rapid onset and peak glucose-lowering effect, thereby ensuring mealtime coverage. Subsequently, a flat and long-lasting glucose-lowering effect from IDeg persisted for longer than the clamp duration of $30 \mathrm{~h}$ in all patients. These pharmacodynamic properties are consistent with what has been shown for the individual IAsp and IDeg components [39-42], thus supporting the pharmacokinetic results showing that absorption of IAsp and IDeg is essentially unaffected by their co-formulation in IDegAsp (see Sect. 4.3).

As a consequence of the extended duration of action of IDeg, well beyond $24 \mathrm{~h}$ in all patients $[41,43]$, the glucose- 
(a)
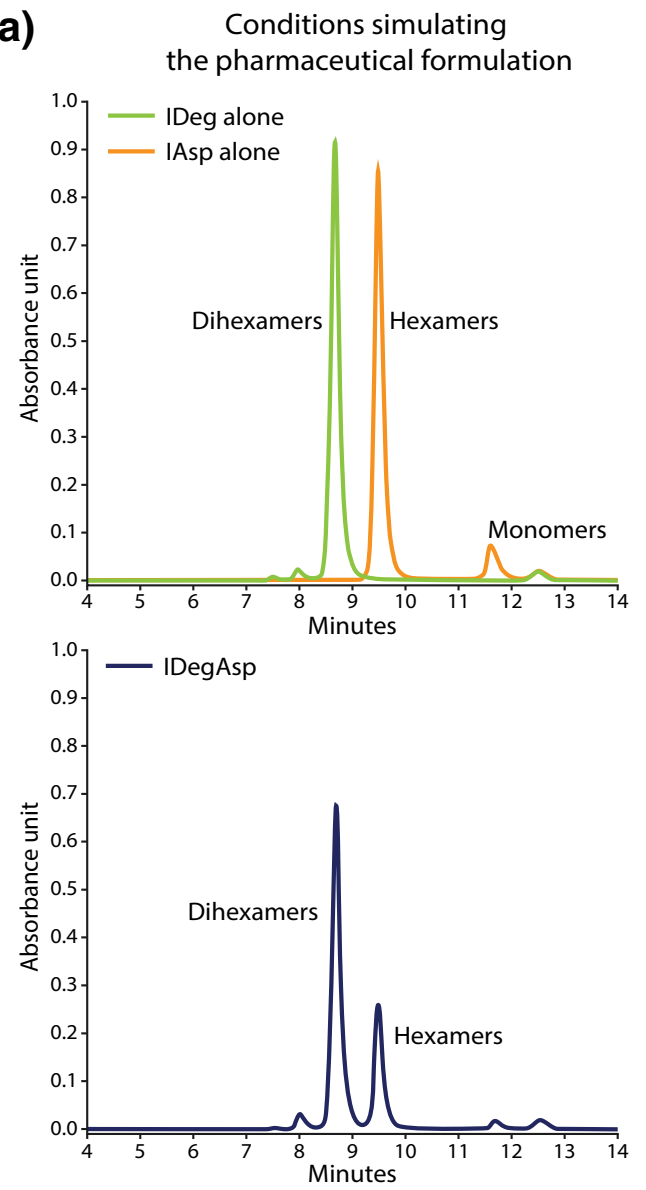

(b)

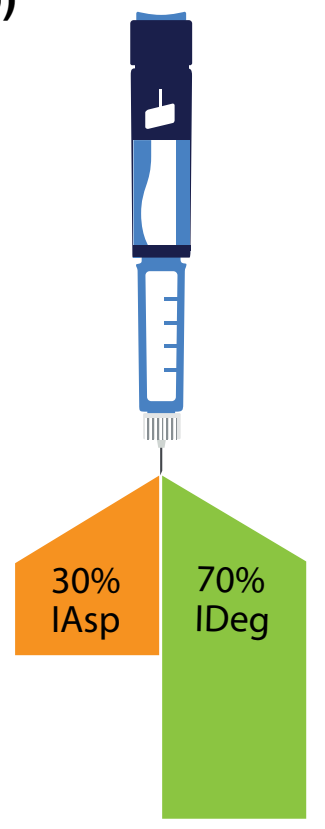

Conditions simulating the subcutaneous environment
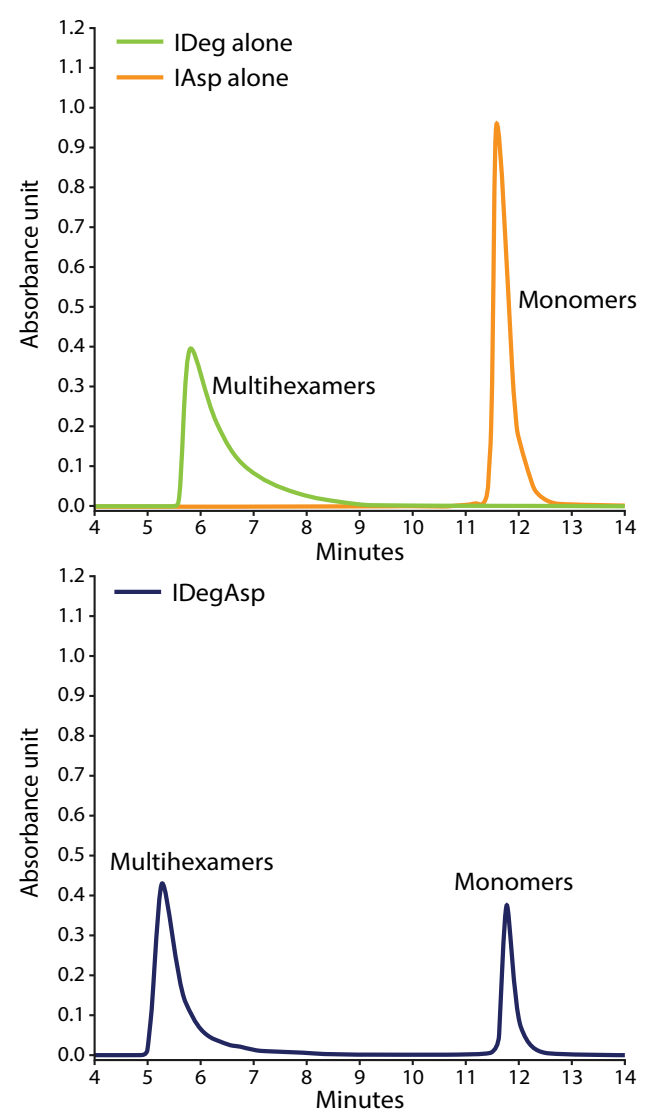

(c)

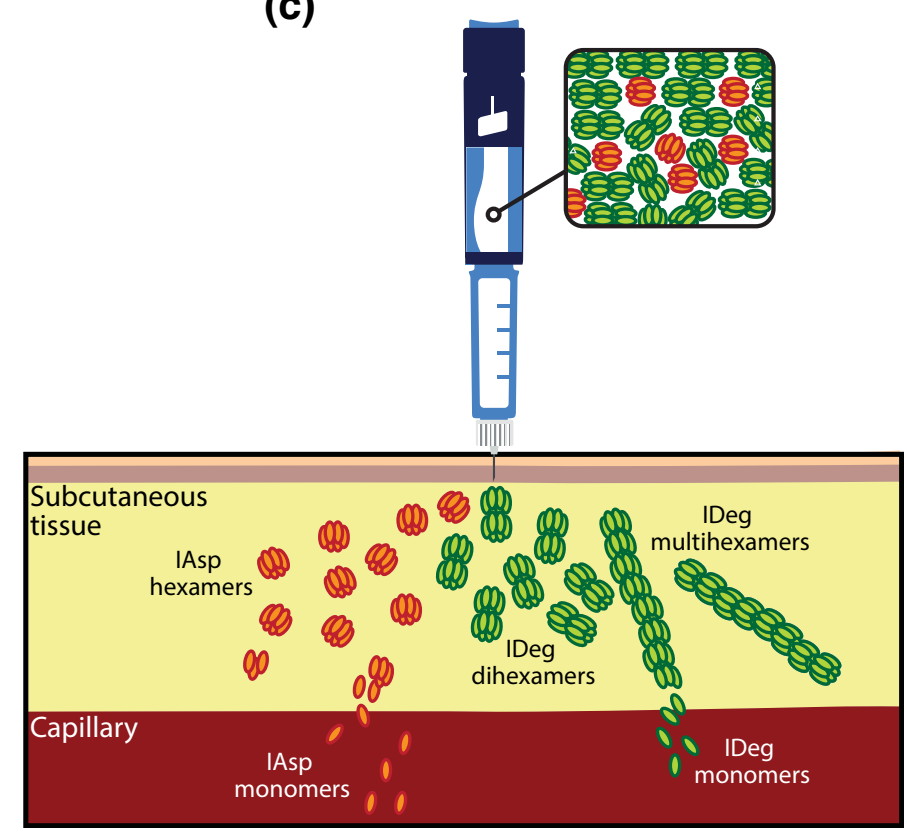


४Fig. 1 Mode of absorption of IDegAsp. a Size-exclusion chromatography of IDegAsp in conditions simulating the pharmaceutical formulation (left panels) and the subcutaneous environment (right panels), and compared with separate IDeg and IAsp formulations (using the same injection volume for both IDegAsp, IDeg and IAsp). Going from left to right on the horizontal axis indicates a shift from large multihexamers, through dihexamers and hexamers, to monomers. Within each panel, the left and right peaks are IDeg and IAsp, respectively. In the pharmaceutical formulation (left panels), IAsp elutes almost solely as hexamers, and IDeg elutes as dihexamers. In the subcutaneous environment (right panels), IAsp elutes almost solely as monomers, and IDeg elutes as multihexamers (modified from Havelund et al. [8]). b IDegAsp is a combination of two soluble insulin analogues (30\% IAsp and $70 \%$ IDeg) in one pen. In the pen, IDeg forms soluble dihexamers at neutral $\mathrm{pH}$, while IAsp stays as hexamers. c Following subcutaneous administration, as illustrated, IDeg dihexamers immediately self-associate to form stable multihexamers in the subcutaneous tissue from which IDeg monomers dissociate slowly and continuously. By contrast, IAsp hexamers promptly dissociate to monomers and are then rapidly absorbed into the circulation. IAsp insulin aspart, IDeg insulin degludec, IDegAsp insulin degludec/insulin aspart

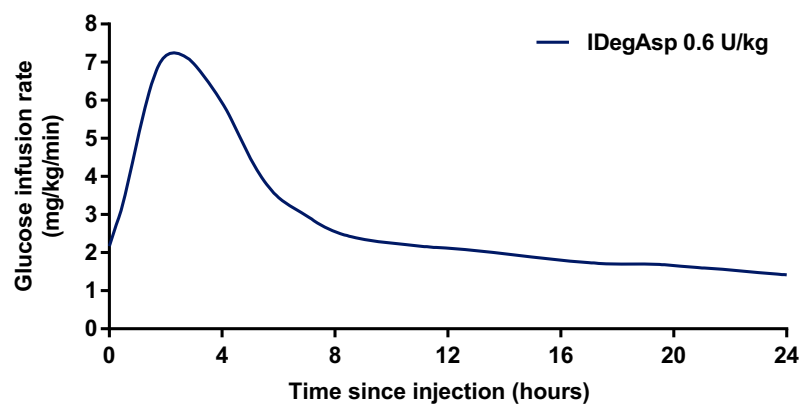

Fig. 2 Mean glucose-lowering effect profile of IDegAsp administered once daily at steady state in patients with T1DM (modified from Heise et al. [9]. IDegAsp insulin degludec/insulin aspart, T1DM type 1 diabetes mellitus

lowering effect of IDeg builds up during the first days of once-daily dosing and reaches a plateau within 2-3 days [44]. For the same reason, the steady-state glucose-lowering effect of IDegAsp is increased compared with single-dose treatment. This has been shown by comparing the glucose-lowering effect profiles of $0.6 \mathrm{U} / \mathrm{kg}$ IDegAsp after single dose [10] and at steady state [9]. As expected, a parallel upshift in the glucose-lowering effect profile from single dose to steady state occurred, with no change in the shape and size of the bolus-related initial peak corresponding to the mealtime coverage (Fig. 3).

The results of a dose-response study in patients with T1DM with single doses of IDegAsp (0.4, 0.6 and $0.8 \mathrm{U} / \mathrm{kg})$ supported dose proportionality for the glucose-lowering effect, since the $95 \%$ confidence interval (CI) for the logdose slope for both the glucose-lowering effect over $24 \mathrm{~h}$ ( $\mathrm{AUC}_{\mathrm{GIR}, 0-24 \mathrm{~h}}$; log-dose slope 1.19, $95 \%$ CI 0.99-1.40) and maximum glucose-lowering effect $\left(\mathrm{GIR}_{\max }\right.$; log-dose slope $0.89,95 \%$ CI $0.66-1.13)$ included $1.00[10,45]$.

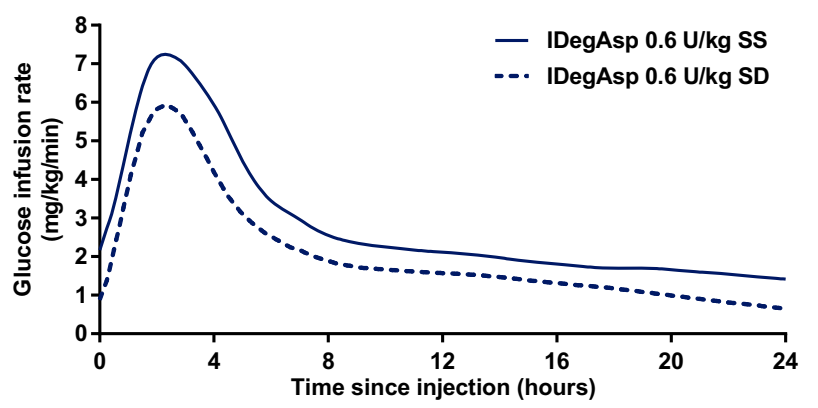

Fig. 3 Mean glucose-lowering effect profiles for $0.6 \mathrm{U} / \mathrm{kg}$ IDegAsp after a single dose and at steady state during once-daily dosing in patients with T1DM (modified from Heise et al. [10]). IDegAsp insulin degludec/insulin aspart, $S D$ single dose, $S S$ steady state, $T 1 D M$ type 1 diabetes mellitus

\subsection{Glucose-Lowering Effect of IDegAsp Compared with Biphasic Insulin Aspart 30 (BIAsp 30)}

The single-dose glucose-lowering effect profiles have been compared between IDegAsp and BIAsp 30 at three doses $(0.4,0.6$ and $0.8 \mathrm{U} / \mathrm{kg}$ ) in patients with T1DM [10]. Since both IDegAsp and BIAsp 30 contain rapid-acting IAsp, the onset of action and shape of the glucose-lowering effect profiles during the initial $4 \mathrm{~h}$ were similar for IDegAsp and BIAsp 30, including comparable time to $\mathrm{GIR}_{\max }\left(\mathrm{tGIR}_{\max }\right)$ (Fig. 4). Beyond approximately $4 \mathrm{~h}$, the glucose-lowering effect of IDegAsp rapidly declined from its maximum peak until approximately 6-7 h post-dose, followed by a flat and stable action from the IDeg component. In contrast, the glucose-lowering effect of BIAsp 30 steadily declined from the peak level and approached zero approximately $18-22 \mathrm{~h}$ post-dose, thus showing a 'shoulder effect' between 6 and $12 \mathrm{~h}$ post-dose attributable to the overlapping action of the soluble and protaminated fractions of IAsp in BIAsp 30 (Fig. 4).

As discussed in Sect. 3.2, the steady-state glucoselowering effect of IDegAsp is greater than after a single dose as a consequence of the long duration of action of IDeg. In contrast, the glucose-lowering effect of BIAsp 30 returns to zero less than $24 \mathrm{~h}$ after dose administration, i.e. before administration of the next dose in a once-daily dose regimen. Consequently, the glucose-lowering effect profile of BIAsp 30 after a single dose reflects clinical practice during once-daily dosing, while this is not the case for IDegAsp. For this reason, the absolute effects of single doses of IDegAsp and BIAsp 30 must be compared with caution. Both $\mathrm{AUC}_{\mathrm{GIR}, 0-24 \mathrm{~h}}$ as well as $\mathrm{GIR}_{\max }$ were lower after a single dose of $0.6 \mathrm{U} / \mathrm{kg}$ IDegAsp than after a single dose of $0.6 \mathrm{U} / \mathrm{kg}$ BIAsp 30 [10]. As expected, at steady state, both the $\mathrm{AUC}_{\mathrm{GIR}, 0-24 \mathrm{~h}}$ and the $\mathrm{GIR}_{\max }$ for IDegAsp were greater than after a single dose $[9,10]$. However, it is important to note that given the persistent shape of the 


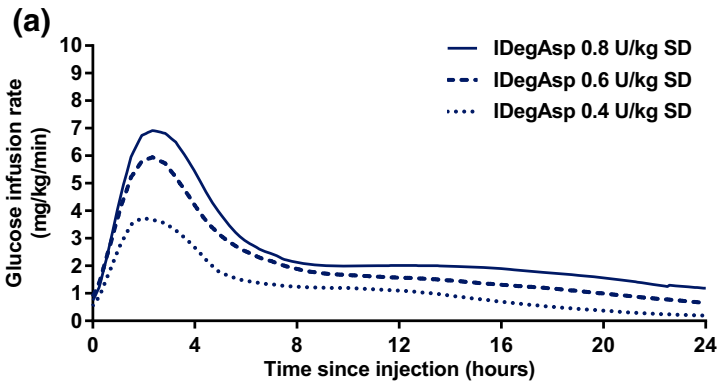

Fig. 4 Mean glucose-lowering effect profiles for single doses of 0.4, 0.6 and $0.8 \mathrm{U} / \mathrm{kg}$ (a) IDegAsp and (b) BIAsp 30 in patients with T1DM (modified from Heise et al. [10]). BIAsp 30 biphasic insulin

glucose-lowering effect profile of IDegAsp after a single dose and at steady state (Fig. 3), single-dose comparisons between IDegAsp and BIAsp 30 may be performed as long as these only focus on the shape of the glucose-lowering effect profiles rather than the absolute effect level.

\subsection{IDegAsp Administered Twice Daily}

IDegAsp may be administered once or twice daily with the main meal(s) as per patient needs and lifestyle preferences $[46,47]$. The glucose-lowering effect profile of IDegAsp administered twice daily at steady state has been studied by simulation using a pharmacokinetic/pharmacodynamic model based on data obtained in the study evaluating IDegAsp once daily in patients with T1DM [9]. The results suggested that the distinct peak effect, as well as the separate and flat basal effect, were retained following each dose (Fig. 5).

The duration of action of IDegAsp is longer than $30 \mathrm{~h}$ as a result of the extended duration of action of the IDeg component [9]. It may be questioned whether such an insulin product can be administered twice daily, as indicated for IDegAsp, without the potential risk of 'insulin stacking' [48]. Several lines of evidence alleviate such concerns. First, several studies with IDeg have shown that serum IDeg concentrations increase during the first days of

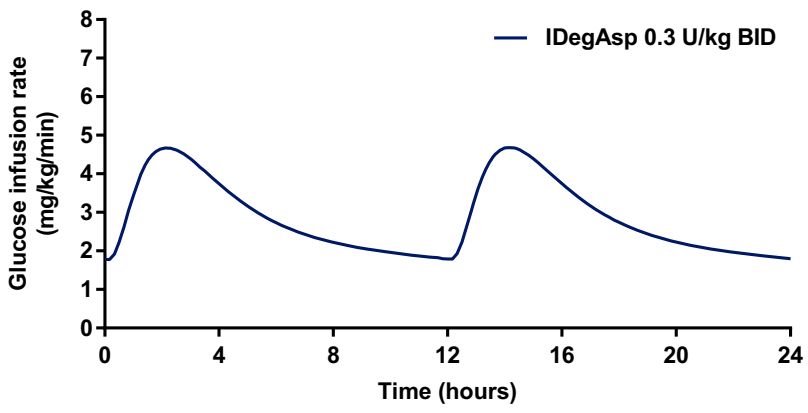

Fig. 5 Simulated mean glucose-lowering effect profile for $0.3 \mathrm{U} / \mathrm{kg}$ IDegAsp administered twice daily at steady state in patients with T1DM (modified from Heise et al. [9]). BID twice daily, IDegAsp insulin degludec/insulin aspart, TIDM type 1 diabetes mellitus

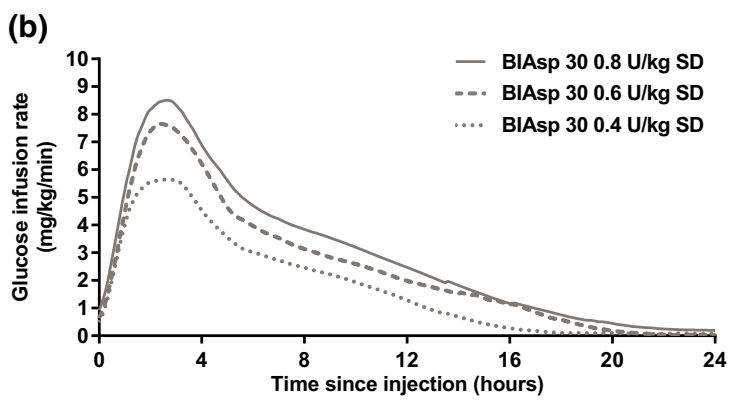

aspart 30, IDegAsp insulin degludec/insulin aspart, $S D$ single dose, TIDM type 1 diabetes mellitus

once-daily dosing, before reaching a plateau within 2-3 days. Thereafter, the exposure level of serum IDeg is unchanged from day to day (Fig. 6a) [44]. Second, in a multiple-dose regimen, the plateau levels of exposure and effect depend only on the total daily dose rather than the dosing frequency [49]. The dosing frequency only influences the peak-to-trough ratio, i.e. the difference between the minimum and maximum concentration or effect within a dosing interval [49]. This means that as long as the same total daily IDegAsp dose is administered, once-daily versus twice-daily dosing of IDegAsp at steady state will result in the same total glucose-lowering effect over the day. The total glucose-lowering effect originating from each of the two components in IDegAsp will also remain unaffected. The only differences will be that the peak-to-trough ratio for the glucose-lowering effect of the basal IDeg component will be smaller with twice-daily dosing, and that the glucose-lowering effect of the IAsp component will be split over two dose administrations (Fig. 6b). This can be seen when comparing the 24-h glucose-lowering effect profiles of $0.6 \mathrm{U} / \mathrm{kg}$ IDegAsp once daily (Fig. 2) and $0.3 \mathrm{U} / \mathrm{kg}$ IDegAsp twice daily (Fig. 5).

\subsection{Variability in Glucose-Lowering Effect}

A common problem in the management of glucose control is the need for exogenous insulin to provide the same glucose-lowering effect from injection to injection in the same individual, usually measured as the withinsubject variability in glucose-lowering effect $[50,51]$. No studies have investigated the within-subject variability in glucose-lowering effect for IDegAsp. However, since the pharmacodynamic properties of IDeg and IAsp appear to not be affected by their co-formulation in IDegAsp, the within-subject variability in glucose-lowering effect for IDeg and IAsp separately should provide a good indicator for IDegAsp also.

The within-subject variability in glucose-lowering effect for IDeg has been compared with IGlar in patients with 
Fig. 6 Steady-state concept for IDegAsp during once- and twice-daily dosing. a When IDegAsp is administered once daily, the IDeg component essentially reaches steady state within 2-3 days due to the approximately $25 \mathrm{~h}$ half-life for IDeg. b At steady state, the glucose-lowering effect from the basal IDeg component is similar regardless of whether IDegAsp is administered once or twice daily, as long as the total daily dose of IDegAsp is unchanged. IDeg insulin degludec, IAsp insulin aspart, IDegAsp insulin degludec/ insulin aspart (a)

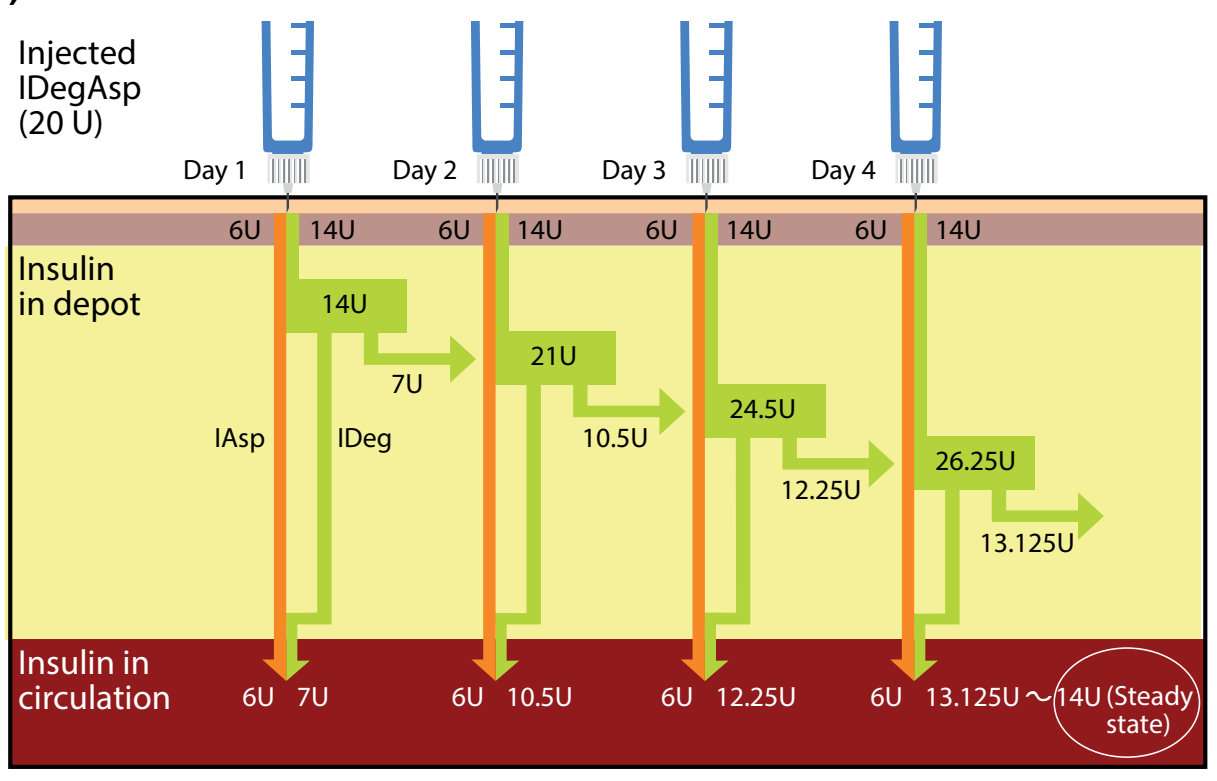

(b)

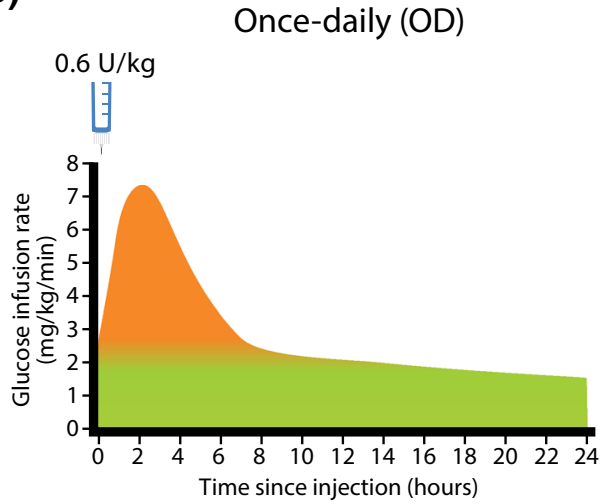

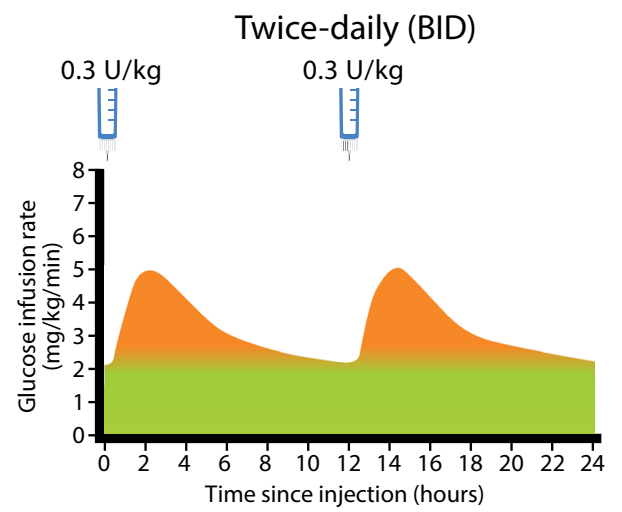

T1DM who were treated with $0.4 \mathrm{U} / \mathrm{kg}$ IDeg or IGlar for 12 days and participated in a 24-h euglycaemic clamp at steady state on days 6, 9 and 12 [52]. IDeg had four-times lower within-subject variability in the total glucose-lowering effect (coefficient of variation 20 vs. $82 \% ; p<0.0001$ ) compared with IGlar [52]. To put this further into context, previous studies in patients with T1DM have shown within-subject coefficients of variation for 24-h glucoselowering effect of 68,48 and $27 \%$ for neutral protamine hagedorn (NPH) insulin, IGlar and IDet, respectively [53], and 99 and $48 \%$ for IGlar and protaminated insulin lispro, respectively [54]. The relatively low within-subject variability for IDeg and IDet is likely because they are formulated as solutions, they stay in solution after subcutaneous injection, their protraction occurs via formation of multi-/dihexamers and they both bind reversibly to albumin in the circulation, thereby providing a buffer effect [55].

One study investigating the within-subject variability in glucose-lowering effect of IAsp reported that the within- subject coefficient of variation was $16 \%$ for GIR $_{\max }$ and generally in the range of 10-20\% for various pharmacodynamic endpoints in healthy volunteers [56]. These values were comparable with those observed for regular human insulin [56]. Altogether, the within-subject variability in glucose-lowering effect of the individual components of IDegAsp is reported to be low. It is therefore speculated that IDegAsp will also have relatively low day-to-day variability in glucose-lowering effect.

\section{Pharmacokinetic Characteristics of IDegAsp}

\subsection{Pharmacokinetic Data Collection}

In the studies investigating the pharmacokinetic properties of IDegAsp, serum IDeg concentrations were measured by a validated IDeg-specific enzyme-linked immunosorbent assay (ELISA), while serum IAsp concentrations were quantified by a validated IAsp-specific ELISA. 
It is important to emphasise that the serum concentrations of IDeg and IAsp cannot be directly compared and are not additive, as serum concentrations of IDeg and IAsp differ by several orders of magnitude, due to the reversible albuminbinding of IDeg in the circulation. This complicates the translation from pharmacokinetic results on the individual IDeg and IAsp components to pharmacodynamic results for IDegAsp, and makes the clinical interpretation of pharmacokinetic results with IDegAsp difficult.

It is expected that the pharmacokinetic profiles of the individual IDeg and IAsp components are preserved in the IDegAsp co-formulation [8] (Sect. 4.3). Consequently, pharmacokinetic results generated after dosing with IDeg or IAsp alone would be representative for the pharmacokinetic properties of the two components in the IDegAsp product. For these reasons, this review focuses on the pharmacokinetic properties of IDegAsp to a limited extent only. The reader is referred to review articles on the pharmacokinetic properties of the separate IDeg and IAsp products $[57,58]$.

\subsection{Pharmacokinetic Properties of IDegAsp}

Clinical steady state for IDeg is obtained within 2-3 days of once-daily IDeg dosing [44], and therefore it can be anticipated that also after 2-3 days of once-daily IDegAsp dosing, clinical steady state will occur for the basal IDeg component. In a multiple-dose study with IDegAsp in patients with T1DM, exposure of the IDeg component was evenly distributed across the 24-h dosing interval at steady state, as indicated by a mean ratio of $\mathrm{AUC}_{\mathrm{IDeg}, 0-12 \mathrm{~h}, \mathrm{SS}} /$ $\mathrm{AUC}_{\mathrm{IDeg}, \tau, \mathrm{SS}}$ of 0.51 [9].

The IAsp component in IDegAsp has a rapid onset of appearance (9-14 $\mathrm{min}$ ) and a time to maximum concentration of approximately $80 \mathrm{~min}[9,11]$, suggesting that IAsp maintains its rapid absorption properties when combined with IDeg in IDegAsp.

\subsection{Pharmacological Implications of Co-Formulating IDeg and IAsp}

In order to investigate the impact of co-formulating IDeg and IAsp on the pharmacokinetic and pharmacodynamic properties of each of the two components, a single-dose study was conducted comparing the administration of IDegAsp with corresponding separate simultaneous administrations of IDeg and IAsp [45]. Thus, dose levels of the two components were matched to their respective fractions in IDegAsp (70\% IDeg and $30 \%$ IAsp). While the pharmacokinetic profile of IDeg was unchanged by co-formulation with IAsp, the pharmacokinetic profile of IAsp was slightly skewed to the right [45]. However, there was no significant impact on $\mathrm{GIR}_{\max }$ or $\mathrm{AUC}_{\mathrm{GIR}, 0-6 \mathrm{~h}}$, which both reflect the effect of the
IAsp component, or on $\mathrm{AUC}_{\mathrm{GIR}, 0-24 \mathrm{~h}}$ [45]. Furthermore, the 24-h glucose-lowering effect profiles were comparable following injection of IDegAsp and corresponding separate simultaneous injections of IDeg and IAsp (Fig. 7).

\section{Pharmacological Properties of IDegAsp Across Different Patient Populations}

\subsection{Children and Adolescents with Diabetes}

In a study comparing the pharmacokinetic and mealtime pharmacodynamic properties of IDegAsp in children (aged 6-11 years) and adolescents (12-17 years) with those in adults with T1DM, no apparent age-group differences were observed in total plasma glucose-lowering effect of IDegAsp or in maximum plasma glucose concentration in a 6-h standardised meal test after single-dose administration of $0.5 \mathrm{U} / \mathrm{kg}$ IDegAsp [11] (Fig. 8). Furthermore, the onset of appearance of IAsp in IDegAsp occurred equally early in all age groups (9-14 min post-dosing), and IDeg was detectable in serum for the whole pharmacokinetic sampling period of $57 \mathrm{~h}$ in all subjects, independent of age. These findings support that the rapid onset and distinct peak action from the IAsp component, and the steady basal glucoselowering effect due to the IDeg component, as observed in adult patients, are preserved in younger age groups. Total exposure and/or maximum concentration of IDeg and IAsp differed, to some extent, between children and adults [11]. These observed differences might be explained by a combination of greater interindividual variability in exogenous insulin exposure in children than in adults and the relatively small sample size of the study [11].

It must be emphasised that guidelines from the International Society for Pediatric and Adolescent Diabetes (ISPAD) do not currently recommend administration of premixed insulin formulations to children and adolescents

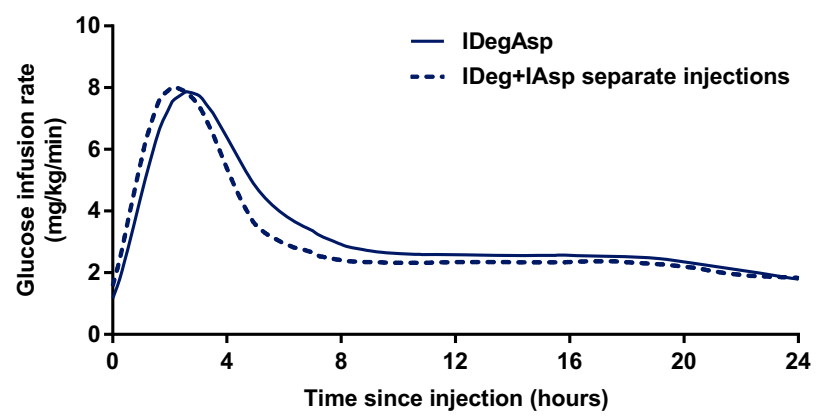

Fig. 7 Mean glucose-lowering effect profiles for administration of $0.92 \mathrm{U} / \mathrm{kg}$ IDegAsp, and for separate simultaneous administrations of $0.28 \mathrm{U} / \mathrm{kg}$ IAsp and $0.64 \mathrm{U} / \mathrm{kg}$ IDeg in patients with T1DM. IAsp insulin aspart, IDeg insulin degludec, IDegAsp insulin degludec/ insulin aspart, T1DM type 1 diabetes mellitus 


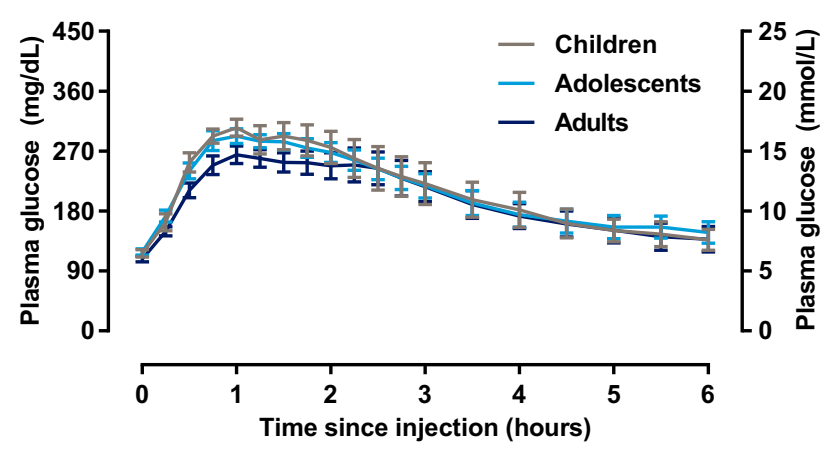

Fig. 8 Mean plasma glucose profiles (and standard error of the mean) in a 6-h meal test after single-dose administration of $0.5 \mathrm{U} / \mathrm{kg}$ IDegAsp in children, adolescents and adults with T1DM (from Biester et al. [11]). IDegAsp insulin degludec/insulin aspart, T1DM type 1 diabetes mellitus

[59]. Accordingly, fixed combination products, where individual components cannot be individually titrated, may not always be appropriate for children, but could be used under strict medical supervision in cases where replacement of suboptimal dosing regimens and/or improvement of treatment compliance is necessary [11].

\subsection{Elderly Patients with Diabetes}

In a euglycaemic clamp study evaluating the pharmacological properties of $0.5 \mathrm{U} / \mathrm{kg}$ IDegAsp administered as a single dose in elderly patients, the distinct prandial and basal glucose-lowering effects of IDegAsp observed in younger adults were preserved in elderly patients aged $>65$ years with T1DM [12] (Fig. 9a). The AUC $\mathrm{AIR}, 0-24 \mathrm{~h}$ was similar in elderly patients and in younger adults (mean ratio of elderly/younger adults 1.01, $95 \%$ CI 0.69-1.47) and there were also no age-group differences in other pharmacodynamic endpoints, such as $\mathrm{AUC}_{\mathrm{GIR}, 0-6 \mathrm{~h}}, \mathrm{GIR}_{\max }$ and $\mathrm{tGIR}_{\max }$ [12]. Likewise, the total exposure of both IAsp and IDeg components were comparable between elderly and younger adult patients [12].

Brunner et al. used a population pharmacokinetic/ pharmacodynamic model to simulate steady-state glucose-lowering effect profiles from the single-dose results, and showed comparable glucose-lowering effect of IDegAsp in elderly and younger adult patients following both once- and twice-daily dosing of IDegAsp [12] (Fig. 9b, c). It may be concluded that, also in elderly patients with diabetes, IDegAsp provides peak action due to IAsp, as well as separate and sustained basal glucoselowering effect from IDeg.

\subsection{Patients with Renal Impairment}

No pharmacokinetic studies with IDegAsp have been conducted to date in patients with renal impairment.

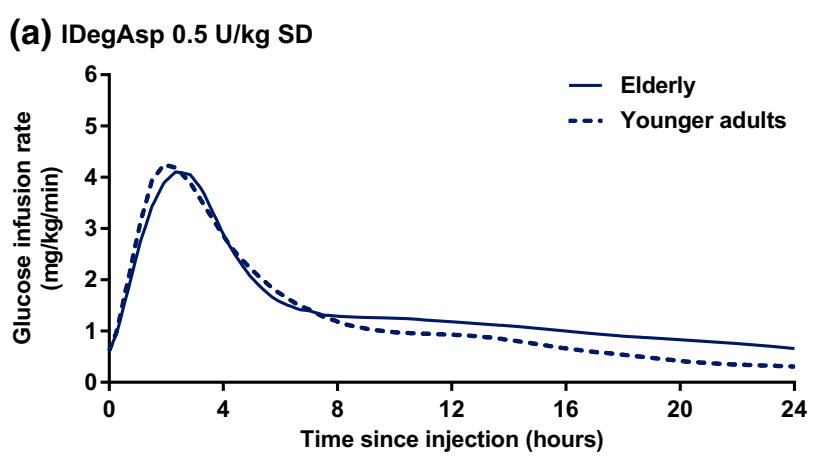

(b) IDegAsp $0.5 \mathrm{U} / \mathrm{kg}$ SS OD

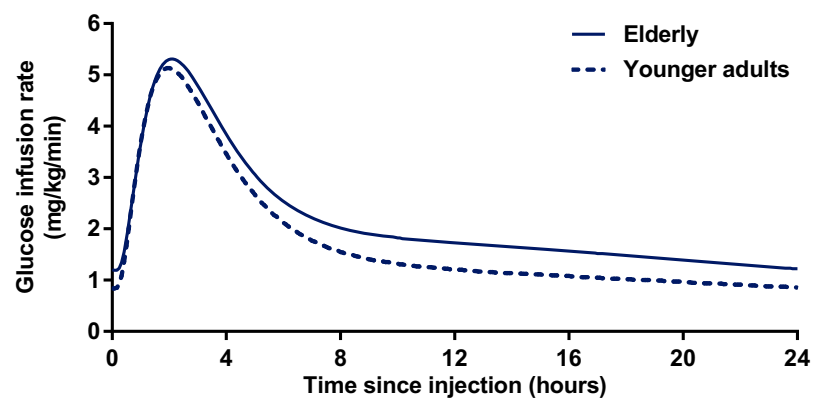

(c) IDegAsp $0.25 \mathrm{U} / \mathrm{kg}$ SS BID

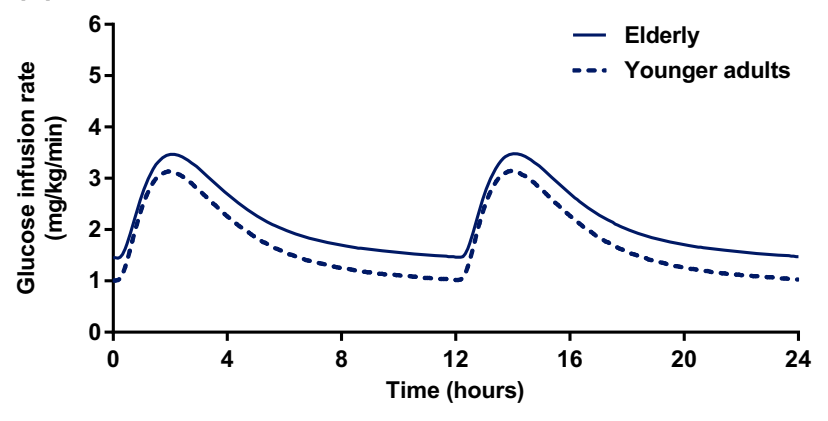

Fig. 9 Mean glucose-lowering effect profiles after administration of IDegAsp in elderly and younger adults with T1DM. a Following a single dose of $0.5 \mathrm{U} / \mathrm{kg}$ IDegAsp. b At steady state during once-daily dosing of $0.5 \mathrm{U} / \mathrm{kg}$ IDegAsp. c At steady state during twice-daily dosing of $0.25 \mathrm{U} / \mathrm{kg}$ IDegAsp (modified from Brunner et al. [12] under the terms of the Creative Commons Attribution-NonCommercial 4.0 International License [http://creativecommons.org/licenses/ by-nc/4.0/]). BID twice daily, IDegAsp insulin degludec/insulin aspart, $O D$ once daily, $S D$ single dose, $S S$ steady state, TIDM type 1 diabetes mellitus

However, since the individual pharmacokinetic properties of IDeg and IAsp are preserved in IDegAsp, pharmacokinetic results after dosing of IDeg or IAsp alone in patients with renal impairment should also be representative for IDegAsp. In T1DM patients with normal renal function or different degrees of renal impairment, there were no significant linear correlations between creatinine clearance and any of the pharmacokinetic endpoints after a single dose of $0.08 \mathrm{U} / \mathrm{kg}$ IAsp [60]. In subjects with normal renal function, and in patients with mild, moderate or severe renal impairment, or end-stage renal disease (ESRD), no 
significant relationship was found between creatinine clearance and total exposure, maximum concentration or clearance after administration of $0.4 \mathrm{U} / \mathrm{kg}$ IDeg [61]. In addition, total exposure, maximum concentration and clearance of IDeg were similar in patients with ESRD compared with subjects with normal renal function, and haemodialysis had no impact on the pharmacokinetic profile of IDeg [61]. It is therefore concluded, based on pharmacokinetic results for IDeg and IAsp, that dose titration of IDegAsp can be performed with no special precautions in patients with diabetes and renal impairment compared with those having normal renal function.

\subsection{Patients with Hepatic Impairment}

No pharmacokinetic studies with IDegAsp have been conducted to date in patients with hepatic impairment. Thus, pharmacokinetic results after dosing of IDeg or IAsp alone in patients with hepatic impairment may be considered as representative for IDegAsp in the following. In subjects with normal hepatic function or patients with different degrees of hepatic impairment, regression analysis of several pharmacokinetic endpoints revealed no significant linear correlations with Child-Pugh Score after a single dose of $0.06 \mathrm{U} / \mathrm{kg}$ IAsp [60]. In patients with mild, moderate or severe hepatic impairment, compared with subjects with normal hepatic function, the protracted pharmacokinetic properties of IDeg were maintained, with no significant differences in absorption or clearance between groups [62]. It is therefore concluded that dose titration of IDegAsp needs no special precautions in patients with diabetes and hepatic impairment compared with those having normal hepatic function.

\subsection{Japanese Patients with Diabetes}

Race and ethnic background may influence the pharmacological properties of a drug $[63,64]$. It is therefore relevant to evaluate the impact of race and/or ethnicity on the pharmacological properties of a new insulin. A euglycaemic glucose clamp study of a single dose of IDegAsp in Japanese patients with T1DM showed that in this patient population, the glucose-lowering effect profile of IDegAsp was characterised by separate prandial and basal action from the IAsp and IDeg components [13]. As also seen in Caucasian patients with diabetes, the glucose-lowering effect profile of IDegAsp was elevated relative to the single-dose profile when simulated to steady state in Japanese patients with T1DM [13] (Fig. 10). Furthermore, it demonstrated a rapid onset and a peak action from IAsp, as well as a separate and sustained basal glucose-lowering effect due to IDeg [13] (Fig. 10). It is concluded that the pharmacodynamic properties of IDegAsp in Japanese patients with T1DM are consistent with those seen in Caucasian patients with T1DM.

\section{Implications of IDegAsp Pharmacological Properties in Clinical Use}

IDegAsp is the first combination of two individual insulin analogues delivered in a single pen. IDegAsp provides both long, flat and stable basal glucose-lowering effect and prandial insulin coverage, and the pharmacodynamic properties of IDegAsp are consistent with its individual components (Sect. 3). The distinct peak and the separate and flat basal effects are retained during once-daily dosing as well as twice-daily dosing and appear to be preserved across several different patient populations, including the elderly, children, adolescents, Japanese patients and those with hepatic or renal impairment (Sect. 5). As summarised in Table 1, in large phase III clinical trials, IDegAsp has been shown to provide effective glycaemic control, addressing both fasting and postprandial glucose control, with a relatively low risk of hypoglycaemia in both insulinnaïve and insulin-experienced patients with diabetes. Table 2 presents an overview of the relation between the various clinical benefits of IDegAsp and its key pharmacological properties. The following subsections will address the clinical applicability of the results obtained in the IDegAsp phase III trials compared with three other currently available treatment options: premixed insulin, basal-bolus regimens and basal-only therapy.

\subsection{Comparison with BIAsp 30}

The efficacy and safety of IDegAsp have been compared with those of BIAsp 30 in three trials in insulin-naïve or insulin-experienced patients with T2DM [16, 17, 19]. Due to the treat-to-target approach of these trials, IDegAsp provided effective overall glycaemic control comparable to

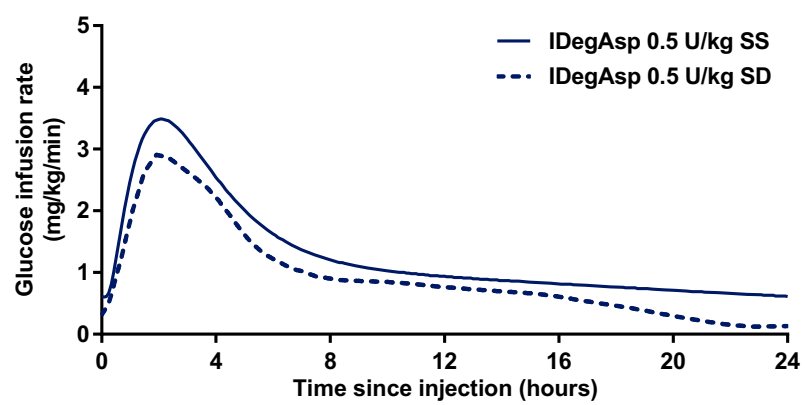

Fig. 10 Mean glucose-lowering effect profiles for $0.5 \mathrm{U} / \mathrm{kg}$ IDegAsp after a single dose and at steady state during once-daily dosing in Japanese patients with T1DM (modified from Haahr et al. [13]). IDegAsp insulin degludec/insulin aspart, $S D$ single dose, $S S$ steady state, T1DM type 1 diabetes mellitus 
BIAsp 30 (Table 1). Fasting plasma glucose (FPG) reduction was superior for IDegAsp compared with BIAsp 30 , which is probably partly a consequence of the extended duration of action of IDeg in IDegAsp compared with the protaminated fraction of IAsp in BIAsp 30. Furthermore, the low within-subject day-to-day variability in glucoselowering effect of the IDeg component should allow for aggressive titration to low FPG targets without being limited by unacceptable rates of nocturnal hypoglycaemia (Table 2).

Hypoglycaemic episodes can adversely affect daily activities such as exercise, work and sleep [65]. The occurrence of hypoglycaemia and the fear of future episodes can affect the clinical success of diabetes treatment and has been highlighted as a reason for aiming at less ambitious glycaemic targets and for reducing the insulin dose $[2,66]$. In the two global trials comparing IDegAsp with BIAsp 30, IDegAsp resulted in significantly lower rates of overall and nocturnal hypoglycaemia [16, 19], consistent with the results of a meta-analysis of the two trials in insulin-experienced patients [67]. The reduced risk of hypoglycaemia with IDegAsp is probably due to its distinct prandial and basal glucose-lowering effects with no 'shoulder effect'. The lower day-to-day variability in the glucose-lowering effect of IDegAsp presumably contributes further to the low rate of hypoglycaemia observed compared with BIAsp 30 (Table 2).

IDegAsp can be administered once or twice daily with the main meal(s) and provides the option of flexible timing of administration as long as it is taken with the largest meal(s) $[46,47]$. The potential for flexible dosing is based on the extended duration of action of IDeg in IDegAsp,

Table 1 Summary of efficacy and hypoglycaemia results in phase III trials with IDegAsp

\begin{tabular}{|c|c|c|c|c|c|c|c|}
\hline \multirow[t]{2}{*}{ Study name } & \multirow[t]{2}{*}{$\begin{array}{l}\text { Study } \\
\text { population }\end{array}$} & \multirow[t]{2}{*}{$\begin{array}{l}\text { Treatment duration } \\
\text { and IDegAsp } \\
\text { regimen }\end{array}$} & \multirow[t]{2}{*}{ Comparator } & \multicolumn{2}{|c|}{$\begin{array}{l}\text { Difference in efficacy } \\
\text { with IDegAsp vs. } \\
\text { comparator (estimated } \\
\text { treatment difference) }\end{array}$} & \multicolumn{2}{|c|}{$\begin{array}{l}\text { Difference in the rate of } \\
\text { hypoglycaemia with IDegAsp vs. } \\
\text { comparator ( } \% \text { difference) }\end{array}$} \\
\hline & & & & $\mathrm{HbA}_{1 \mathrm{c}}(\%)$ & $\begin{array}{l}\text { FPG } \\
(\mathrm{mmol} / \mathrm{L})\end{array}$ & $\begin{array}{l}\text { Overall } \\
\text { confirmed } \\
\text { hypoglycaemia }\end{array}$ & $\begin{array}{l}\text { Nocturnal } \\
\text { confirmed } \\
\text { hypoglycaemia }\end{array}$ \\
\hline \multicolumn{8}{|l|}{ Versus premixed } \\
\hline $\begin{array}{l}\text { BOOST }^{\circledR} \text { START } \\
\text { TWICE DAILY } \\
{[19]}\end{array}$ & $\begin{array}{l}\text { T2DM; insulin- } \\
\text { naïve }\end{array}$ & 26 weeks; bid & BIAsp 30 & $\begin{array}{l}0.02 \text {; non- } \\
\text { inferior }\end{array}$ & -1.00 & $54 \downarrow$ & $75 \downarrow$ \\
\hline $\begin{array}{l}\text { BOOST }^{\circledR} \\
\text { INTENSIFY } \\
\text { PREMIX I [16] }\end{array}$ & $\begin{array}{l}\text { T2DM; insulin- } \\
\text { treated }\end{array}$ & 26 weeks; bid & BIAsp 30 & $\begin{array}{l}-0.03 \text {; non- } \\
\text { inferior }\end{array}$ & -1.14 & $32 \downarrow$ & $73 \downarrow$ \\
\hline $\begin{array}{l}\text { BOOST }^{\circledR} \\
\text { INTENSIFY ALL } \\
{[17]}\end{array}$ & $\begin{array}{l}\text { T2DM; Asian, } \\
\text { insulin- } \\
\text { treated }\end{array}$ & 26 weeks; bid & BIAsp 30 & $\begin{array}{l}0.05 \text {; non- } \\
\text { inferior }\end{array}$ & -1.06 & $0 \leftrightarrow$ & $33 \downarrow$ \\
\hline \multicolumn{8}{|l|}{ Versus basal-bolus } \\
\hline BOOST $^{\circledR} \mathrm{T} 1$ [14] & T1DM & 26 weeks; od & IDet + IAsp & $\begin{array}{l}-0.05 \text {; non- } \\
\text { inferior }\end{array}$ & 0.23 & $9 \downarrow$ & $37 \downarrow$ \\
\hline BOOST $^{\circledR}$ T1 [20] & T1DM & 52 weeks; od & IDet + IAsp & $\begin{array}{l}-0.10 \text {; non- } \\
\text { inferior }\end{array}$ & -0.07 & $5 \downarrow$ & $38 \downarrow$ \\
\hline $\begin{array}{l}\text { BOOST }^{\circledR} \text { TWICE } \\
\text { DAILY VS. BB } \\
{[18]}\end{array}$ & $\begin{array}{l}\text { T2DM; insulin- } \\
\text { treated }\end{array}$ & 26 weeks; bid & IDeg + IAsp & $\begin{array}{l}0.18 \text {; non- } \\
\text { significant }\end{array}$ & -0.31 & $19 \downarrow$ & $20 \downarrow$ \\
\hline \multicolumn{8}{|l|}{ Versus basal-only } \\
\hline $\begin{array}{l}\text { BOOST }^{\circledR} \\
\text { INTENSIFY } \\
\text { BASAL [21] }\end{array}$ & $\begin{array}{l}\text { T2DM; insulin- } \\
\text { treated }\end{array}$ & 26 weeks; od & IGlar & $\begin{array}{l}-0.03 \text {; non- } \\
\text { inferior }\end{array}$ & 0.33 & $43 \uparrow$ & $20 \downarrow$ \\
\hline $\begin{array}{l}\text { BOOST }^{(\mathbb{}}{ }^{\text {JAPAN }} \\
\text { OD [15] }\end{array}$ & $\begin{array}{l}\text { T2DM; } \\
\text { Japanese, } \\
\text { insulin-naïve }\end{array}$ & 26 weeks; od & IGlar & $\begin{array}{l}-0.28 ; \\
\text { superior }\end{array}$ & 0.15 & $27 \downarrow$ & $25 \downarrow$ \\
\hline
\end{tabular}

Results shown in bold indicate a statistically significant difference between IDegAsp and the comparator

$B B$ basal-bolus, BIAsp 30 biphasic insulin aspart 30, bid twice daily, $F P G$ fasting plasma glucose, $H b A_{l c}$ glycosylated haemoglobin, IAsp insulin aspart, IDegAsp insulin degludec/insulin aspart, IDeg insulin degludec, IDet insulin detemir, IGlar insulin glargine, od once daily, TIDM type 1 diabetes mellitus, $T 2 D M$ type 2 diabetes mellitus 
Table 2 Clinical benefits of IDegAsp and their relation to IDegAsp pharmacological properties

\begin{tabular}{llc}
\hline Clinical benefits & Pharmacological properties & $\begin{array}{l}\text { Relevant section(s) for discussion } \\
\text { of pharmacological properties }\end{array}$ \\
\hline $\begin{array}{l}\text { Versus premixed } \\
\text { Improved FPG control }\end{array}$ & Duration of action $>30 \mathrm{~h}$ & Section 3.2 \\
& Low within-subject day-to-day variability & Section 3.5 \\
Reduced hypoglycaemia risk & No 'shoulder' effect & Section 3.3 \\
& Low within-subject day-to-day variability & Section 3.5 \\
Mealtime flexibility & Duration of action of basal component $>30 \mathrm{~h}$ & Section 3.4 \\
& Distinct prandial and basal glucose-lowering effects during & Section 3.4 \\
No need for resuspension & od and bid dosing & Section 2.3 \\
Versus basal-bolus & Existence of insulin degludec and insulin aspart as separate & Sections 3.2 and 3.4 \\
Reduced number of daily injections & and stable soluble forms in the co-formulation & Distinct prandial and basal glucose-lowering effects during \\
Versus basal-only & od and bid dosing & Section 3.2 \\
Additional flexible mealtime coverage & Distinct prandial and basal glucose-lowering effects during & od dosing \\
\hline
\end{tabular}

bid twice daily, FPG fasting plasma glucose, IDegAsp insulin degludec/insulin aspart, od once daily

which implies that during repeated dosing the glucoselowering effect at a given time is the sum of overlapping action from several injections [44]. Variations in the dosing interval will therefore have limited impact on the glucoselowering effect from the basal component of IDegAsp. The possibility of varying the time of administration from day to day was confirmed in a clinical trial with IDeg in patients with T2DM, where dosing intervals of 8-40 h did not compromise glycaemic control or safety compared with IGlar administration at the same time each day [68].

As discussed in Sect. 3.4, twice-daily dosing of IDegAsp may give rise to questions about 'stacking' because of the long duration of action of IDeg in IDegAsp. However, it was concluded that once-daily versus twicedaily dosing of IDegAsp results in comparable glucoselowering effect from the basal component as long as the same total daily IDegAsp dose is administered. The safety of IDegAsp in a twice-daily regimen is also indicated from the clinical trial results showing significantly lower rates of overall and nocturnal hypoglycaemia with IDegAsp than with BIAsp 30 administered twice daily. Dependent on the carbohydrate load of the main meals, some patients following an IDegAsp twice-daily regimen might prefer to split the daily dose unevenly. This scenario has not been investigated in clinical trials, but theoretically it would be expected to have only minor impact on the daily glucoselowering effect from the basal component based on the above discussion of flexible dosing. With twice-daily dosing of IDegAsp, the minimum interval between doses is determined by the duration of action of the prandial component, and hence would need to be $4-6 \mathrm{~h}$.
Taken together, compared with the widely used premixed insulin, BIAsp 30, IDegAsp represents a new therapeutic option, both as insulin initiation and for treatment intensification in patients with T2DM. IDegAsp provides effective glycaemic control, with a markedly lower risk of hypoglycaemia, and offers simplicity of use for patients because resuspension before injection is not needed.

\subsection{Comparison with Basal-Bolus Regimens}

The burden associated with multiple daily injections is still one of the most important issues for insulin-treated diabetes patients [69]. Accordingly, basal-bolus regimens are perceived as complex and can induce some patients to regularly omit insulin [2, 70]. IDegAsp, possibly supplemented with rapid-acting insulin at the remaining meals, represents a simple alternative to separate basal and bolus injections. In patients with $\mathrm{T} 2 \mathrm{DM}$ previously receiving basal insulin, IDegAsp twice daily was compared with a basal-bolus regimen of IDeg once daily plus IAsp (Table 1) [18]. Both intensification regimens were effective in improving glycaemic control and, even though non-inferiority between treatments could not be confirmed, there were no significant treatment differences that could imply an effect on clinical usefulness [18]. Nonetheless, total insulin dose was lower and weight gain was less with IDegAsp [18]. This indicates that IDegAsp provides an effective and convenient regimen for those patients with T2DM who need intensified insulin therapy but at the same time find it challenging to follow a more complex regimen with frequent glucose monitoring [71]. 
Although IDegAsp is particularly suited for patients with T2DM, trials have shown that it may also be used in those with T1DM. In patients with T1DM, IDegAsp once daily was compared with IDet once or twice daily with IAsp at the remaining meals (Table 1) [14, 20]. IDegAsp showed similar glycaemic control, comparable rate of overall hypoglycaemia, reduced risk of nocturnal hypoglycaemia and lower total insulin dose, with fewer injections than with IDet $[14,20]$. IDegAsp may not be suitable in those patients with T1DM who prefer the flexibility of separately titrating the prandial and basal components. However, in those patients with T1DM who would not consider self-adjusting their insulin doses, IDegAsp may be an option, with fewer daily injections and thus reduced treatment burden.

\subsection{Comparison with Basal-Only Therapy}

Treatment guidelines state that early use of insulin therapy should be considered in patients with T2DM [1]. While initiation with basal insulin is the most common regimen in many countries, initiation with premixed or combination insulin is still a widely used strategy. Addressing postprandial hyperglycaemia may be important for achieving overall glycaemic control, particularly in patients with $\mathrm{HbA}_{1 \mathrm{c}}$ approaching target [72, 73]. Thus, IDegAsp could be an option for initiation of insulin, especially in patients who need to achieve postprandial glycaemic control.

In clinical trials comparing IDegAsp once daily and IGlar once daily in patients with T2DM, IDegAsp was well tolerated and provided similar or improved overall glycaemic control versus IGlar, with the additional benefit of postprandial glucose control at one main meal, and with nocturnal hypoglycaemia rates comparable to those observed with IGlar (Table 1) $[15,21]$. In one of the trials, a higher rate of overall hypoglycaemia was observed with IDegAsp versus IGlar [21]. This might have been due to the trial requirement that IDegAsp should always be administered with the same meal, whereas the largest meal of the day in terms of carbohydrate load may have shifted from day to day [21]. When using IDegAsp once daily, changes in dose and the option to move the injection time to match any significant daily variations in carbohydrate eating patterns should be considered to minimise the risk of postprandial hypoglycaemia. Results of a recent study of IDegAsp once daily in insulin-naïve patients with T2DM showed that selftitration of IDegAsp using either a simple algorithm with fewer self-measured blood glucose measurements or a stepwise algorithm with longer titration intervals but more self-measured blood glucose measurements provided comparable glucose control [74]. These alternative titration methods may offer patients a personalised insulin titration regimen tailored to individual needs [74].
Altogether, it seems that IDegAsp is an attractive treatment option for initiation of insulin therapy in patients with T2DM, combining the simplicity of a single injection with the benefits of addressing both fasting and postprandial glucose control. These advantages of IDegAsp may encourage patients with T2DM to initiate insulin treatment earlier and to improve their compliance, thereby possibly facilitating achievement of glycaemic targets.

\section{Conclusions}

IDegAsp is the first soluble combination of two insulin analogues (IDeg and IAsp) designed to provide both basal and mealtime insulin coverage in one injection. Preservation of the pharmacokinetic and pharmacodynamic profiles of the individual components in IDegAsp sets it apart from conventional premixed insulin products. IDegAsp retains the clear separation of basal and prandial effects during both once- and twice-daily dosing. Moreover, the pharmacological properties of IDegAsp appear to be maintained across several different patient populations, including the elderly, children, adolescents, Japanese patients and those with hepatic or renal impairment. Translation of its pharmacokinetic and pharmacodynamic properties into favourable clinical benefits makes treatment with IDegAsp superior to premixed formulations, as well as a viable alternative to basal-only and basal-bolus therapy. Overall, IDegAsp has the potential to address certain barriers in the treatment and management of patients with diabetes.

Acknowledgments The authors would like to thank Carsten Roepstorff, PhD, CR Pharma Consult, Copenhagen, Denmark, for providing medical writing support funded by Novo Nordisk.

\section{Compliance with Ethical Standards}

Funding This article was funded by Novo Nordisk.

Conflict of interest Hanne Haahr and Edmond G. Fita are employees and shareholders of Novo Nordisk. Tim Heise's institution received research grants from Adocia, AstraZeneca, Becton-Dickinson, Biocon, Boehringer Ingelheim, Dance Biopharm, Eli Lilly, Grünenthal, Gulf Pharmaceutical Industries, Johnson \& Johnson, Marvel, MedImmune, Medtronic, Novartis, Novo Nordisk, Roche Diagnostics, Sanofi, Senseonics, and Zealand Pharma. In addition, Tim Heise is member of advisory boards for Novo Nordisk, and received speaker honoraria and travel grants from Eli Lilly, Mylan and Novo Nordisk.

Open Access This article is distributed under the terms of the Creative Commons Attribution-NonCommercial 4.0 International License (http://creativecommons.org/licenses/by-nc/4.0/), which permits any noncommercial use, distribution, and reproduction in any medium, provided you give appropriate credit to the original author(s) and the source, provide a link to the Creative Commons license, and indicate if changes were made. 


\section{References}

1. Inzucchi SE, Bergenstal RM, Buse JB, et al. Management of hyperglycaemia in type 2 diabetes, 2015: a patient-centered approach. Update to a position statement of the American Diabetes Association and the European Association for the Study of Diabetes. Diabetologia. 2015;58:429-42.

2. Peyrot M, Barnett AH, Meneghini LF, Schumm-Draeger PM. Insulin adherence behaviours and barriers in the multinational Global Attitudes of Patients and Physicians in Insulin Therapy study. Diabet Med. 2012;29:682-9.

3. Ross SA, Tildesley HD, Ashkenas J. Barriers to effective insulin treatment: the persistence of poor glycemic control in type 2 diabetes. Curr Med Res Opin. 2011;27:13-20.

4. Garber AJ, Ligthelm R, Christiansen JS, Liebl A. Premixed insulin treatment for type 2 diabetes: analogue or human? Diabetes Obes Metab. 2007;9:630-9.

5. Liebl A, Prusty V, Valensi P, et al. Ten years of experience with biphasic insulin aspart 30: from drug development to the latest clinical findings. Drugs. 2012;72:1495-520.

6. Jehle PM, Micheler C, Jehle DR, Breitig D, Boehm BO. Inadequate suspension of neutral protamine Hagendorn (NPH) insulin in pens. Lancet. 1999;354:1604-7.

7. Jia W, Xiao X, Ji Q, et al. Comparison of thrice-daily premixed insulin (insulin lispro premix) with basal-bolus (insulin glargine once-daily plus thrice-daily prandial insulin lispro) therapy in east Asian patients with type 2 diabetes insufficiently controlled with twice-daily premixed insulin: an open-label, randomised, controlled trial. Lancet Diabetes Endocrinol. 2015;3:254-62.

8. Havelund S, Ribel U, Hubálek F, Hoeg-Jensen T, Wahlund PO, Jonassen I. Investigation of the physico-chemical properties that enable co-formulation of basal insulin degludec with fast-acting insulin aspart. Pharm Res. 2015;32:2250-8.

9. Heise T, Nosek L, Roepstorff C, Chenji S, Klein O, Haahr H. Distinct prandial and basal glucose-lowering effects of insulin degludec/insulin aspart (IDegAsp) at steady state in subjects with type 1 diabetes mellitus. Diabetes Ther. 2014;5:255-65.

10. Heise T, Nosek L, Klein O, Coester H, Svendsen AL, Haahr H. Insulin degludec/insulin aspart produces a dose-proportional glucose-lowering effect in subjects with type 1 diabetes mellitus. Diabetes Obes Metab. 2015;17:659-64.

11. Biester T, Danne T, Bläsig S, et al. Pharmacokinetic and prandial pharmacodynamic properties of insulin degludec/insulin aspart in children, adolescents, and adults with type 1 diabetes. Pediatr Diabetes. 2016;. doi:10.1111/pedi.12358 (Epub 18 Jan 2016).

12. Brunner M, Pieber T, Korsatko S, Kojzar H, Svendsen AL, Haahr $\mathrm{H}$. The distinct prandial and basal pharmacodynamics of IDegAsp observed in younger adults are preserved in elderly subjects with type 1 diabetes. Drugs Aging. 2015;32:583-90.

13. Haahr H, Sasaki T, Bardtrum L, Ikushima I. Insulin degludec/ insulin aspart in Japanese patients with type 1 diabetes mellitus: distinct prandial and basal glucose-lowering effects. J Diabetes Investig. 2016;7:574-80.

14. Hirsch IB, Bode B, Courreges JP, et al. Insulin degludec/insulin aspart administered once daily at any meal, with insulin aspart at other meals versus a standard basal-bolus regimen in patients with type 1 diabetes: a 26-week, phase 3, randomized, open-label, treat-to-target trial. Diabetes Care. 2012;35:2174-81.

15. Onishi Y, Ono Y, Rabøl R, Endahl L, Nakamura S. Superior glycaemic control with once-daily insulin degludec/insulin aspart versus insulin glargine in Japanese adults with type 2 diabetes inadequately controlled with oral drugs: a randomized, controlled phase 3 trial. Diabetes Obes Metab. 2013;15:826-32.

16. Fulcher GR, Christiansen JS, Bantwal G, BOOST: Intensify Premix I Investigators, et al. Comparison of insulin degludec/ insulin aspart and biphasic insulin aspart 30 in uncontrolled, insulin-treated type 2 diabetes: a phase $3 \mathrm{a}$, randomized, treat-totarget trial. Diabetes Care. 2014;37:2084-90.

17. Kaneko S, Chow F, Choi DS, BOOST: Intensify All Trial Investigators, et al. Insulin degludec/insulin aspart versus biphasic insulin aspart 30 in Asian patients with type 2 diabetes inadequately controlled on basal or pre-/self-mixed insulin: a 26-week, randomised, treat-to-target trial. Diabetes Res Clin Pract. 2015;107:139-47.

18. Rodbard HW, Cariou B, Pieber TR, Endahl LA, Zacho J, Cooper JG. Treatment intensification with an insulin degludec (IDeg)/insulin aspart(IAsp) co-formulation twice daily compared with basal IDeg and prandial IAsp in type 2 diabetes: a randomized, controlled phase III trial. Diabetes Obes Metab. 2016;18:274-80.

19. Franek E, Haluzík M, Canecki Varžić S, et al. Twice-daily insulin degludec/insulin aspart provides superior fasting plasma glucose control and a reduced rate of hypoglycaemia compared with biphasic insulin aspart 30 in insulin-naïve adults with Type 2 diabetes. Diabet Med. 2016;33:497-505.

20. Hirsch IB, Franek E, Mersebach H, Bardtrum L, Hermansen K. Safety and efficacy of insulin degludec/insulin aspart with bolus mealtime insulin aspart compared with standard basal-bolus treatment in people with type 1 diabetes: 1-year results from a randomized clinical trial $\left(\right.$ BOOST $^{\circledR}$ T1). Diabet Med. 2016;. doi:10.1111/dme.13068 (Epub 16 Jan 2016).

21. Kumar S, Jang HC, Guvener ND, Skjøth TV, Endahl L, Bode B. Efficacy and safety of once-daily insulin degludec/insulin aspart compared with once-daily insulin glargine in participants with type 2 diabetes: a randomized, treat-to-target study. Diabet Med. 2016;. doi:10.1111/dme.13125 (Epub 30 Mar 2016).

22. Lepore M, Pampanelli S, Fanelli C, et al. Pharmacokinetics and pharmacodynamics of subcutaneous injection of long-acting human insulin analog glargine, NPH insulin, and ultralente human insulin and continuous subcutaneous infusion of insulin lispro. Diabetes. 2000;49:2142-8.

23. Plank J, Bodenlenz M, Sinner F, et al. A double-blind, randomized, dose-response study investigating the pharmacodynamic and pharmacokinetic properties of the long-acting insulin analog detemir. Diabetes Care. 2005;28:1107-12.

24. Heise T, Eckers U, Kanc K, Nielsen JN, Nosek L. The pharmacokinetic and pharmacodynamic properties of different formulations of biphasic insulin aspart: a randomized, glucose clamp, crossover study. Diabetes Technol Ther. 2008;10:479-85.

25. Rave K, Heinemann L, Puhl L, et al. Premixed formulations of insulin lispro. Activity profiles in type 1 diabetic patients. Diabetes Care. 1999;22:865-6.

26. Liebl A, Prager R, Binz K, et al. Comparison of insulin analogue regimens in people with type 2 diabetes mellitus in the PREFER Study: a randomized controlled trial. Diabetes Obes Metab. 2009;11:45-52.

27. Riddle MC, Rosenstock J, Vlajnic A, Gao L. Randomized, 1-year comparison of three ways to initiate and advance insulin for type 2 diabetes: twice-daily premixed insulin versus basal insulin with either basal-plus one prandial insulin or basal-bolus up to three prandial injections. Diabetes Obes Metab. 2014;16:396-402.

28. Evans M, Schumm-Draeger PM, Vora J, King AB. A review of modern insulin analogue pharmacokinetic and pharmacodynamic profiles in type 2 diabetes: improvements and limitations. Diabetes Obes Metab. 2011;13:677-84.

29. Cengiz E, Tamborlane WV, Martin-Fredericksen M, Dziura J, Weinzimer SA. Early pharmacokinetic and pharmacodynamic effects of mixing lispro with glargine insulin: results of glucose clamp studies in youth with type 1 diabetes. Diabetes Care. 2010;33:1009-12. 
30. Cengiz E, Swan KL, Tamborlane WV, Sherr JL, Martin M, Weinzimer SA. The alteration of aspart insulin pharmacodynamics when mixed with detemir insulin. Diabetes Care. 2012;35:690-2.

31. Poon K, King AB. Glargine and detemir: safety and efficacy profiles of the long-acting basal insulin analogs. Drug Healthc Patient Saf. 2010;2:213-23.

32. Havelund S, Plum A, Ribel U, et al. The mechanism of protraction of insulin detemir, a long-acting, acylated analog of human insulin. Pharm Res. 2004;21:1498-504.

33. EMA. Tresiba: summary of product characteristics. 2015. http:// www.ema.europa.eu/docs/en_GB/document_library/EPAR_-_ Product_Information/human/002498/WC500138940.pdf. Accessed 16 Sept 2016.

34. FDA. Tresiba: prescribing information. 2015. http://www. accessdata.fda.gov/drugsatfda_docs/label/2015/203314lbl.pdf. Accessed 16 Sept 2016.

35. Jonassen I, Havelund S, Hoeg-Jensen T, Steensgaard DB, Wahlund PO, Ribel U. Design of the novel protraction mechanism of insulin degludec, an ultra-long-acting basal insulin. Pharm Res. 2012;29:2104-14.

36. Steensgaard DB, Schluckebier G, Strauss HM, et al. Ligandcontrolled assembly of hexamers, dihexamers, and linear multihexamer structures by the engineered acylated insulin degludec. Biochemistry. 2013;52:295-309.

37. DeFronzo RA, Tobin JD, Andres R. Glucose clamp technique: a method for quantifying insulinsecretion and resistance. Am J Physiol. 1979;237:E214-23.

38. Arnolds S, Kuglin B, Kapitza C, Heise T. How pharmacokinetic and pharmacodynamic principles pave the way for optimal basal insulin therapy in type 2 diabetes. Int J Clin Pract. 2010;64:1415-24.

39. Heinemann L, Heise T, Jørgensen LN, Starke AA. Action profile of the rapid acting insulin analogue: human insulin B28Asp. Diabet Med. 1993;10:535-9.

40. Østerberg O, Erichsen L, Ingwersen SH, Plum A, Poulsen HE, Vicini P. Pharmacokinetic and pharmacodynamic properties of insulin aspart and human insulin. J Pharmacokinet Pharmacodyn. 2003;30:221-35

41. Heise T, Nosek L, Bøttcher SG, Hastrup H, Haahr H. Ultra-longacting insulin degludec has a flat and stable glucose-lowering effect in type 2 diabetes. Diabetes Obes Metab. 2012;14:944-50.

42. Heise T, Hovelmann U, Nosek L, Hermanski L, Bøttcher SG, Haahr H. Comparison of the pharmacokinetic and pharmacodynamic profiles of insulin degludec and insulin glargine. Expert Opin Drug Metab Toxicol. 2015;11:1193-201.

43. Kurtzhals P, Heise T, Strauss HM, et al. Multi-hexamer formation is the underlying basis for the ultra-long glucose-lowering effect of insulin degludec. Diabetologia. 2011;54:S426.

44. Heise T, Korsatko S, Nosek L, et al. Steady state is reached within 2-3 days of once-daily administration of degludec, a basal insulin with an ultralong duration of action. J Diabetes. 2016;8:132-8.

45. Novo Nordisk. Insulin degludec and insulin degludec/insulin aspart treatment to improve glycemic control in patients with diabetes mellitus. Briefing document. FDA Endocrinologic and Metabolic Drug Advisory Committee. 2012. http://www.fda.gov/ downloads/AdvisoryCommittees/CommitteesMeetingMaterials/ Drugs/EndocrinologicandMetabolicDrugsAdvisoryCommittee/ UCM327017.pdf. Accessed 16 Sept 2016.

46. EMA. Ryzodeg: summary of product characteristics. 2016. http:// www.ema.europa.eu/docs/en_GB/document_library/EPAR_-_ Product_Information/human/002499/WC500139011.pdf. Accessed 16 Sept 2016.

47. FDA. Ryzodeg: prescribing information. 2016. http://www. accessdata.fda.gov/drugsatfda_docs/label/2016/203313s004lbl. pdf. Accessed 16 Sept 2016.
48. Heise T, Meneghini LF. Insulin stacking versus therapeutic accumulation: understanding the differences. Endocr Pract. 2014;20:75-83.

49. Rowland M, Tozer TN. Clinical pharmacokinetics and pharmacodynamics: concepts and applications. 4th ed. Philadelphia: Lippincott Williams \& Wilkins; 2007.

50. Heinemann L. Variability of insulin action: does it matter? Insulin. 2008;3:37-45.

51. Vora J, Heise T. Variability of glucose-lowering effect as a limiting factor in optimizing basal insulin therapy: a review. Diabetes Obes Metab. 2013;15:701-12.

52. Heise T, Hermanski L, Nosek L, Feldman A, Rasmussen S, Haahr $H$. Insulin degludec: four times lower pharmacodynamic variability than insulin glargine under steady-state conditions in type 1 diabetes. Diabetes Obes Metab. 2012;14:859-64.

53. Heise T, Nosek L, Rønn BB, et al. Lower within-subject variability of insulin detemir in comparison to NPH insulin and insulin glargine in people with type 1 diabetes. Diabetes. 2004;53:1614-20.

54. Ocheltree SM, Hompesch M, Wondmagegnehu ET, Morrow L, Win K, Jacober SJ. Comparison of pharmacodynamic intrasubject variability of insulin lispro protamine suspension and insulin glargine in subjects with type 1 diabetes. Eur J Endocrinol. 2010;163:217-23.

55. Kurtzhals P. Engineering predictability and protraction in a basal insulin analogue: the pharmacology of insulin detemir. Int J Obes Relat Metab Disord. 2004;28:S23-8.

56. Heinemann L, Weyer C, Rauhaus M, Heinrichs S, Heise T. Variability of the metabolic effect of soluble insulin and the rapid-acting insulin analog insulin aspart. Diabetes Care. 1998;21:1910-4.

57. Haahr H, Heise T. A review of the pharmacological properties of insulin degludec and their clinical relevance. Clin Pharmacokinet. 2014;53:787-800

58. Lindholm A, Jacobsen LV. Clinical pharmacokinetics and pharmacodynamics of insulin aspart. Clin Pharmacokinet. 2001;40:641-59.

59. Danne T, Bangstad HJ, Deeb L, Clinical Practice Consensus Guidelines ISPAD, et al. Insulin treatment in children and adolescents with diabetes. Pediatr Diabetes. 2014;15:115-34.

60. Holmes G, Galitz L, Hu P, Lyness W. Pharmacokinetics of insulin aspart in obesity, renal impairment, or hepatic impairment. Br J Clin Pharmacol. 2005;60:469-76.

61. Kiss I, Arold G, Roepstorff C, Bøttcher SG, Klim S, Haahr H. Insulin degludec: pharmacokinetics in patients with renal impairment. Clin Pharmacokinet. 2014;53:175-83.

62. Kupčová V, Arold G, Roepstorff C, Højbjerre M, Klim S, Haahr H. Insulin degludec: pharmacokinetic properties in subjects with hepatic impairment. Clin Drug Investig. 2014;34:127-33.

63. Morello CM. Pharmacokinetics and pharmacodynamics of insulin analogs in special populations with type 2 diabetes mellitus. Int $\mathrm{J}$ Gen Med. 2011;4:827-35.

64. Chen ML. Ethnic or racial differences revisited: impact of dosage regimen and dosage form on pharmacokinetics and pharmacodynamics. Clin Pharmacokinet. 2006;45:957-64.

65. Brod M, Rana A, Barnett AH. Impact of self-treated hypoglycaemia in type 2 diabetes: a multinational survey in patients and physicians. Curr Med Res Opin. 2012;28:1947-58.

66. Leiter L, Yale J, Chiasson J, Harris S, Kleinstiver P, Sauriol L. Assessment of the impact of fear of hypoglycemic episodes on glycemic and hypoglycemia management. Can J Diabetes. 2005;29:186-92.

67. Christiansen JS, Niskanen L, Rasmussen S, Johansen T, Fulcher $\mathrm{G}$. Lower rates of hypoglycemia during maintenance treatment with IDegAsp versus BIAsp 30: a combined analysis of two phase 3a studies in type 2 diabetes. J Diabetes. 2016;8:720-8. 
68. Meneghini L, Atkin SL, Gough SC, et al. The efficacy and safety of insulin degludec given in variable once-daily dosing intervals compared with insulin glargine and insulin degludec dosed at the same time daily: a 26-week, randomized, open-label, parallelgroup, treat-to-target trial in individuals with type 2 diabetes. Diabetes Care. 2013;36:858-64.

69. Rubin RR, Peyrot M, Kruger DF, Travis LB. Barriers to insulin injection therapy: patient and health care provider perspectives. Diabetes Educ. 2009;35:1014-22.

70. Peyrot M, Rubin RR, Kruger DF, Travis LB. Correlates of insulin injection omission. Diabetes Care. 2010;33:240-5.

71. Mosenzon O, Raz I. Intensification of insulin therapy for type 2 diabetic patients in primary care: basal-bolus regimen versus premix insulin analogs: when and for whom? Diabetes Care. 2013;36:S212-8
72. Monnier L, Lapinski H, Colette C. Contributions of fasting and postprandial plasma glucose increments to the overall diurnal hyperglycemia of type 2 diabetic patients. Variations with increasing levels of $\mathrm{HbA}_{1 \mathrm{c}}$. Diabetes Care. 2003;26:881-5.

73. Woerle HJ, Neumann C, Zschau S, et al. Impact of fasting and postprandial glycemia on overall glycemic control in type 2 diabetes. Importance of postprandial glycemia to achieve target HbA1c levels. Diabetes Res Clin Pract. 2007;77:280-5.

74. Park SW, Bebakar WM, Hernandez PG, Macura S, Hersl øv ML, de la Rosa R. Insulin degludec/insulin aspart once daily in Type 2 diabetes: a comparison of simple or stepwise titration algorithms BOOST $^{\circledR}$ : SIMPLE USE). Diabet Med. 2016;. doi:10.1111/dme. 13069 (Epub 16 Jan 2016). 